\title{
Dissecting the politics of "Obamacare": The role of distributive justice, deservingness, and affect.
}

\section{Hanoch, $Y$}

http://hdl.handle.net/10026.1/12436

Journal of Applied Social Psychology

Wiley

All content in PEARL is protected by copyright law. Author manuscripts are made available in accordance with publisher policies. Please cite only the published version using the details provided on the item record or document. In the absence of an open licence (e.g. Creative Commons), permissions for further reuse of content should be sought from the publisher or author. 


\section{JOURNAL OF APPLIED SOCIAL PSYCHOLOGY}

\section{Dissecting the politics of "Obamacare": The role of distributive justice, deservingness, and affect}

\begin{tabular}{|r|l|}
\hline Journal: & Journal of Applied Social Psychology \\
\hline Manuscript ID & 17-JASP-0339.R1 \\
\hline Wiley - Manuscript type: & Original Article \\
\hline Keywords: & $\begin{array}{l}\text { distributive justice, socio-political ideology, deservingness, conservatism, } \\
\text { fairness }\end{array}$ \\
\hline \multicolumn{2}{|c}{} \\
\\
$\begin{array}{r}\text { SCHOLARONE } \\
\text { Manuscripts }\end{array}$ \\
\end{tabular}


Dissecting the politics of "Obamacare":

The role of distributive justice, deservingness, and affect 


\begin{abstract}
Political conservatives (vs. liberals) are commonly thought to oppose government-based policies that promote equal distribution of resources, preferring that resources be distributed based on merit. In a sample of American adults $(n=436)$, distributive fairness perceptions, deservingness, and affective reactions related to the Affordable Care Act (ACA) were examined to better understand the ideological differences in ACA attitudes. Participants completed measures of political orientation, ACA knowledge and attitudes, deservingness, distributive justice principles (i.e. need, equality, merit), anger, and sympathy. Identifying as politically liberal (vs. conservative) and greater knowledge on the ACA predicted greater ACA support. Preferences for the distributive justice principles of equality and need (but not equity) mediated the relation between political orientation and ACA attitudes. Further, conservatives perceived less deservingness and in turn experienced greater anger and opposition to the ACA. Additional exploratory analyses also suggest that the positive path between deservingness and ACA support is moderated by political orientation such that it is stronger among political liberals than conservatives. Implications of the ideological chasm in relation to the ACA are considered.
\end{abstract}

Keywords: distributive justice, socio-political ideology, deservingness, conservatism, fairness. 


\section{Introduction}

The Affordable Care Act (ACA; also known as Obamacare) was one of the most significant changes to healthcare in the U.S. in recent decades. The ACA has been one of the most contentious ideological battles in the U.S.. This ideological divide follows a long-standing gap between political conservatives' and liberals' attitudes towards national health insurance coverage. Health reform has been a political battleground for many years (Kirsch, 2013), from both Roosevelt presidents, Nixon to Obama, and now, Trump. In general, people identifying as conservative prefer individual-based policies and those identifying as liberal favor governmentbased policies (Bodenheimer, 2005). These ideological differences in health insurance coverage preferences reflect a general aid allocation pattern: individuals on the political left are generally more supportive than those on the political right of providing assistance to those in need (e.g., Brandt, 2013; Feather, 1985; Pellegrini, Queirolo, Monarrez, \& Valenzuela, 1997; Reyna, Henry, Korfmacher, \& Tucker, 2005; Shirazi \& Biel, 2005; Skitka \& Tetlock, 1992; 1993).

Public opinion polls, mirroring research on political ideological differences in aid allocation, have revealed a deep chasm between conservatives and liberals since the inception of the ACA (Kirzinger, Sugarman, \& Brodie, 2016). In the midst of legislative efforts to repeal and replace the ACA, a survey by the Kaiser Family Foundation in July 2017 found that overall support for the law was the highest since 2010, standing at 50\%. However, the survey, like many previous ones, showed dramatic differences by political affiliation: Whereas $77 \%$ of Democrats supported the law, only $16 \%$ of Republicans voiced a similar opinion (20\% of Democrats express unfavorable opinion compared to $81 \%$ of Republicans). Efforts to repeal and replace the ACA entirely in 2017, when Republicans regained control of the White House and controlled both chambers of Congress, were unpopular and largely unsuccessful - although the repeal of the 
individual mandate to purchase health insurance was a notable exception. Most of the major provisions of the ACA remain in place and will likely continue to for some time, while Medicaid, the coverage program for low-income families, continues to expand in states that were initial holdouts after the ACA was passed (Rice et al., 2018). Thus, the debate on the ACA specifically, and on universal coverage reform more generally continues to dominate political and social discourse (Kirzinger et al., 2017). This paper extends beyond the well-documented differences in ideological attitudes by examining mechanisms that might explain why the divide on health reform exists. Further, the present research considers potential mechanisms in the context of a real (vs. hypothetical; e.g. Christiansen \& Lavine, 1997) health policy. Specifically, we investigate whether the ideological divide in support for the ACA is due, in part, to differences in what people judge as "fair", whether people perceive recipients as "deserving," and affective reactions related to the ACA. In addition, we explore whether fact-based knowledge of the ACA can inform opinions about the ACA, alongside political orientation.

\section{Distributive Justice}

One reason for the fundamental disparity between those on the political left and political right in providing benefits is a discrepancy in perceptions of fairness. What is "fair" is contingent on how fairness is defined. There are several types of social justice concerns including distributive, procedural, interactional, retributive and restorative justice (see Jost \& Kay, 2010; Sabbagh \& Schmitt, 2016). Of particular relevance to healthcare attitudes, distributive justice focuses on whether people perceive the allocation of resources to achieve policy outcomes, like publicly provided or subsidized insurance coverage, as fair or unfair (Cohen \& Greenberg, 1982; Rawls, 1971). Other social justice concerns are likely relevant to healthcare coverage attitudes; 
however, publicly funded healthcare is fundamentally about the allocation of resources. Hence, in the present paper, we focus on distributive justice.

Theory and research on distributive justice has focused on three types of fairness: equity (sometimes referred to as merit), equality and need (Jasso, Törnblom, \& Sabbagh, 2016; Jost \& Kay, 2010; Taylor, 1997). Each principle represents a unique way to allocate resources. There are several equity theories, but essentially, the principle of equity concerns the distribution of resources based on relative contributions (e.g., hours worked) or liabilities (e.g., procrastinating) (e.g., Adams, 1965; Walster et al., 1973). In contrast, for the principle of equality, outcomes are fair if they divided evenly, regardless of input. Finally, according to the need principle, resources are fair if they are allocated based on necessity (for overviews of distributive justice theories, see Jasso et al., 2016; Jost \& Kay, 2010; Tyler, Boeckmann, Smith, \& Huo, 1997). Thus, fairness of the ACA could be assessed according to three unique distributive justice principles: equity, equality, or need, as is done in the present study.

A variety of personal or contextual factors affect fairness perceptions of and preferences for particular distributive justice principles (see Törnblom, 1992; e.g. Matania \& Yaniv, 2007). Of particular relevance to the present research on U.S. health reform, political conservatives and liberals differ consistently in their distributive justice principle preferences and use. Bierbrauer and Klinger (2002) found that those endorsing left (vs. right) wing attitudes more strongly agreed with items reflecting egalitarian or need-based distributive justice policies. Similarly, Frey and Powell (2005) reported that participants identifying as right (vs. left) wing preferred merit (i.e. equity) over need as a benchmark for assessing distributive fairness, and that those identifying as left (vs. right) wing preferred equality. Although conservatives have an overarching preference for equity and liberals for need and equality, the application of distributive justice principles in 
particular situations can be affected by factors such as the scarcity or abundance of the resource, degree of responsibility of the claimant, and perceived need of the claimant. Skitka and Tetlock (1992), for example, noted that when allocating welfare or health care, conservatives chose not to assist claimants who were personally responsible for their predicament, regardless of whether resources were abundant or not (see also Mitchell, Tetlock, Newman, \& Lerner, 2003; Skitka \& Tetlock, 1993). Liberals, in contrast, aided all claimants when resources were plentiful. Consequently, conservatives in particular, might oppose the ACA, or specific features of it, because it violates their justice principle preferences. Liberals, in comparison, might support the ACA because of their preferences for equality and need. We test these assertions in the current study.

\section{Deservingness}

Ideological differences in how resources should be allocated in health policies can be attributed, in part, to differences in deservingness judgements of claimants (e.g., Medicaid or Medicare beneficiaries) and subsequent affective reactions to claimants. Implicated in deservingness judgements are the degree of responsibility and controllability a claimant has (Feather, 1999; Weiner, 2006). The more responsible a person or group is, and the more controllable the behavior, the more deserving they are of the outcome. This pattern emerges for a variety of policies with greater deservingness predicting more support for providing benefits. This pattern has emerged in the context of social assistance and welfare (e.g., Appelbaum, 2001; Gilens, 1995, 1999; Henry, Reyna, \& Weiner, 2004; Lane, 2001; Nelson, 1999; Skitka \& Tetlock, 1993; Zucker \& Weiner, 1993), home foreclosure assistance (Brandt, 2013), and aid to natural disaster victims (Huddy \& Feldman, 2006; Scott \& Bornstein, 2009; Skitka, 1999). Importantly, people from both ends of the political spectrum attribute behaviors that violate their 
values, like being uninsured, to controllable causes (Morgan, Mullen, \& Skitka, 2010; Skitka et al., 2002). Hence, people might be more apt to perceive insurance coverage as controllable, and consequently undeserving of assistance, if they are inconsistent with their ideological outlook, thereby affecting support for the ACA and its efforts to expand insurance coverage. The influence of deservingness on attitudes about the ACA is tested in the current study.

\section{Affective Reactions}

Deservingness is theorized to inform allocation decisions via its impact on affective reactions to claimants (Rudolph, Roesch, Greitemeyer, \& Weiner, 2004; Weiner, 1980, 2006; Weiner, Osborne, \& Rudolph, 2011). Experiencing negative emotions like anger is associated with perceiving an outcome as more controllable and the person less deserving of aid, whereas experiencing positive emotions like sympathy is associated with perceiving an outcome as less controllable and the person more deserving of assistance (e.g., Brandt, 2013; Skitka, 1999; Zucker \& Weiner, 1993). Applied to the ACA, if a person perceives a group or claimant as undeserving, for example believing it is lower income Americans' personal responsibility to secure health insurance, they are likely to feel angry. If a person perceives a claimant as deserving, they are likely to feel sympathetic. These particular emotions, theoretically, will then inform whether or not aid is provided.

Research investigating resource allocation decisions, at least in the context of healthcare, has shown that political conservatives evaluate most claimants as less deserving, whereas liberals evaluate all claimants as deserving of assistance (Skitka \& Tetlock, 1992; see also Skitka 1999). Liberals report experiencing greater sympathy and less negative affect toward claimants, including individuals and communities personally responsible for their adverse outcome; the reverse characterizes conservatives, such that political conservatives report lower sympathy and 
greater negative affect (Skitka \& Tetlock, 1992; Skitka et al., 2002, Study 5). Hence, liberals’ perceptions of greater deservingness and greater sympathy for the uninsured may explain, in part, their greater support for the ACA compared to conservatives. The posited relationship between deservingness, sympathy for the uninsured, political ideology, and ACA support is examined here.

\section{The Present Research}

In the present study, three main questions were investigated. First, whether the relation between political conservatism (vs. liberalism) and opposition to the ACA could be explained, in part, by distributive justice principle preferences (see Figure 1). Second, whether deservingness and affective reactions explain ideological differences in ACA support (see Figure 2). And third, the relative predictive ability of ACA fact-based knowledge and political orientation.

\section{Method}

\section{Participants and Procedure}

U.S. participants were recruited through Amazon Mechanical Turk (MTurk) to complete a survey entitled "Social, economic and political effects of the Affordable Care Act" (conducted October 14-20, 2015), and paid \$1 U.S. for their participation. Consistent with sample size guidelines outlined by Kline (2005) for conducting path analyses, we aimed to collect a large sample of 400. We collected data from 452 participants. However, we removed 13 duplicate entries, and three cases where the data were incomplete. Our final sample consisted of 436 adults. Participants ranged in age from 20 to $74\left(M_{\text {age }}=36.7, S D=11.8\right)$, with women representing $52.8 \%$ of the sample. With regard to ethnic/racial origin, participants identified as White (81.2\%), African American (6.4\%), Latino (4.1\%), other (1.4\%), 0.7\% did not specify their ethnicity, and less than $2 \%$ identified as Chinese, Filipino, Japanese, or Korean. The 
majority of participants had completed college (40.6\%) or some college (31.7\%). A further $15.1 \%$ had completed high school only, while $11.8 \%$ had a graduate degree. Most participants identified as Democrat (50.5\%), followed by 'other' political party identification (27.5\%), Republican (17.9\%), and no political party (3.2\%).

A comparison with the U.S. census data from 2012 showed that our sample was largely representative of the overall population, although there were more females, Whites, college educated, and the average age was slightly younger than in the population from which they were drawn. Moreover, comparing statistics from a Pew Research study (2015), sample demographics over represent Democrats, and underrepresent independents and Republicans than in the population from which they were drawn. Despite the variation in the sample relative to the general population, MTurk samples have shown to be more representative than student samples of the general population and reliably replicate robust findings in psychology, economics, and political science (see Paolacci \& Chandler, 2014 for a review). After providing consent, participants completed measures of attitudes toward the ACA, distributive justice principle preferences, sympathy and anger about the ACA, deservingness of affordable healthcare coverage, political orientation, knowledge of the ACA, and demographics. Participants then read a debriefing form outlining the specific purpose and hypotheses of the research.

\section{Materials}

Political orientation. Political orientation was assessed with a political self-identification scale (see Jost, 2006). The response scale ranged from 1 (extremely liberal) to 11 (extremely conservative). Higher scores indicated a more conservative ( $v s$. liberal) orientation.

Distributive justice principle preferences. Twelve items were developed based on Skitka and Tetlock (1992) to measure distributive justice principle preferences. Allocation 
preferences for need, equality, and equity were measured across four broader questions that comprised three items each, one for each distributive justice principle. The four broader question stems were as follows: "Business should subsidize health care for...”; "Tax payers should contribute to health care costs for..."; "State governments should pay for health care costs for..."; "Federal government should pay for health care costs for...". Hence, four items each assessed individual differences in allocation preferences specific to healthcare subsidies and support based on need (i.e. healthcare should be distributed to Americans who need it), equality (i.e. healthcare should be distributed equally to all Americans), and equity (i.e. healthcare should be given to those who pay for into it). Participants responded to the items by indicating the extent to which they thought it was fair on a scale from 1 (not at all fair) to 5 (extremely fair). Items for each subscale were averaged with higher scores indicating a greater preference to distribute healthcare resources based on need (Cronbach's $\alpha=.88)$, equality $(\alpha=.86)$, and equity $(\alpha=.86)$.

Deservingness. Deservingness was measured using a 4-item scale. The first two items ("Everyone deserves affordable health care coverage"; "It is only fair that people who cannot afford health care coverage are helped by the government") were modified from Skitka et al. (2002). Participants responded to both items on a scale from 1 (strongly disagree) to 7 (strongly agree). Two additional items were developed by the researchers: "To what extent do lower income Americans deserve subsidies for health care" and "To what extent do Americans deserve affordable health care coverage". Participants responded using a scale from 1 (not at all deserving) to 7 (completely deserving). The four items were averaged with higher scores indicating greater deservingness of claimants $(\alpha=.89){ }^{1}$

Affective reactions. Four items each were used to measure anger and sympathy toward: lower income Americans who receive subsidies, the federal government who provides subsidies 
to lower income Americans, the federal government who imposes regulations on insurance companies, and state governments for expanding Medicaid. Participants responded on a scale from 1 (not at all angry/no sympathy) to 7 (very angry/lots of sympathy). The four anger items were averaged and the four sympathy items were averaged to create scores for anger $(\alpha=.92)$ and sympathy ( $\alpha=.90)$ with higher scores indicating greater anger and sympathy related to the ACA.

Fact-based knowledge about the ACA. To assess fact-based knowledge about the ACA, participants completed an 18-item measure adapted from Gross et al. (2012) and the Kaiser Family Foundation (DiJulio, Firth, \& Brodie, 2015). Participants were asked "Do you think the new law will or will not do the following after the law is fully in effect"? For each of the 18-items participants responded with a yes or no. Example items included: "Require companies that make drugs to pay new feeds to the federal government each year", "Provide discounts on prescriptions to seniors with high drug costs", and "Require insurance companies to charge an additional fee of $\$ 1000$ a year to anyone who buys insurance from them and smokes cigarettes". Scores were created by adding up the number of items answered correctly. Higher scores indicated greater fact-based knowledge about the ACA.

Attitudes toward the ACA. To assess attitudes toward health reform issues, participants read 12 statements adapted from Gross et al. (2012). The items described various health reform issues and policies in the U.S. (e.g. individual mandate, expansion of Medicaid). Participants indicated the degree to which they assessed the issue/policy as favorable on a scale from 1 (extremely unfavorable) to 7 (extremely favorable). Scores were created by averaging responses to the 12 items with higher scores reflecting support (vs. opposition) to the ACA $(\alpha=.78)$. 
Obamacare 12

\section{Results}

Means, standard deviations and correlations among study variables are presented in Table 1. Consistent with predictions, a politically conservative ( $v s$. liberal) orientation was associated with perceiving healthcare distributed according to need and equality as less fair, lower deservingness, greater anger and less sympathy, and more opposition to the ACA. Further, greater deservingness, lower anger, and greater sympathy related to support (vs. opposition) of the ACA. Contrary to hypotheses, political orientation was unrelated to the distributive justice principle of equity. Political conservatism (vs. liberalism) related to less fact-based knowledge about the ACA, and greater fact-based knowledge related to greater support for the ACA. Table 1

Means, standard deviations and correlations between study variables

\begin{tabular}{|c|c|c|c|c|c|c|c|c|c|}
\hline & Mean (SD) & 1 & 2 & 3 & 4 & 5 & 6 & 7 & 8 \\
\hline 1. Political orientation & $4.86(2.85)$ & & & & & & & & \\
\hline 2. Need & $3.67(1.15)$ & $-.45 * *$ & & & & & & & \\
\hline 3. Equality & $3.89(1.04)$ & $-.43 * *$ & $.56^{* *}$ & & & & & & \\
\hline 4. Equity & $3.71(1.02)$ & -.04 & $.34 * *$ & $.24 * *$ & & & & & \\
\hline 5. Deservingness & $5.80(1.42)$ & $-.51 * *$ & $.65^{* *}$ & $.65^{* *}$ & $.20 * *$ & & & & \\
\hline 6. Anger & $2.28(1.58)$ & $.53^{* *}$ & $-.52 * *$ & $-.49 * *$ & $-.10^{*}$ & $-.70 * *$ & & & \\
\hline 7. Sympathy & $4.01(1.82)$ & $-.33 * *$ & $.45^{* *}$ & $.34 * *$ & .02 & $.44 * *$ & $-.39 * *$ & & \\
\hline 8. Support for ACA & $5.51(0.91)$ & $-.46^{* *}$ & $.45^{* *}$ & $.51^{* *}$ & $.20^{* *}$ & $.72 * *$ & $-.58 * *$ & $.28^{* *}$ & \\
\hline 9. ACA knowledge & $13.62(2.48)$ & $-.29 * *$ & $.18^{* *}$ & $.21 * *$ & .09 & $.38 * *$ & $-.40 * *$ & $.09 *$ & $.49 * *$ \\
\hline
\end{tabular}

Note. $N=436 .{ }^{*} p<.05,{ }^{*} p<.001$. ACA=Affordable Care Act. Deservingness (skewness=-1.22) and anger (skewness 1.07) had skewness values above one. Need, equality, equity, ACA attitudes, and ACA knowledge had skewness values between -.64 and -.80). 


\section{The mediating role of distributive justice principles}

To evaluate whether beliefs about how resources should be distributed account, in part, for the relation between political orientation and attitudes toward 'Obamacare', regression analyses were conducted using the PROCESS macro for SPSS version 3.0 (Hayes, 2018) and SPSS version 24 software. Political orientation was entered as the independent variable; need, equality, and equity were entered as simultaneous mediators; and attitudes toward 'Obamacare' was entered as the dependent variable. Confidence interval estimates were based on 5000 bootstrapped samples. Results are shown in Table 2 . Identifying as politically conservative ( $v s$. liberal) significantly predicted perceiving need-based distributions and equality-based distributions as less fair. Contrary to our hypothesis, political orientation did not significantly predict equity. Identifying as politically liberal ( $v s$. conservative), perceiving need-based distributions as fair, and equality-based distributions as fair, all significantly predicted greater support for 'Obamacare', as expected. However, equity did not emerge as a significant predictor $(p=.064)$. Indirect effects were estimated using 5000 bootstrap samples. Consistent with hypotheses, need and equality mediated the relation between greater political conservatism and opposition to 'Obamacare'. Equity was not a significant mediator. Therefore, as hypothesized, the relation between a politically conservative orientation and opposition to the ACA can be explained in part, by the perception that distributing resources to provide healthcare coverage according to need and equality is unfair. 


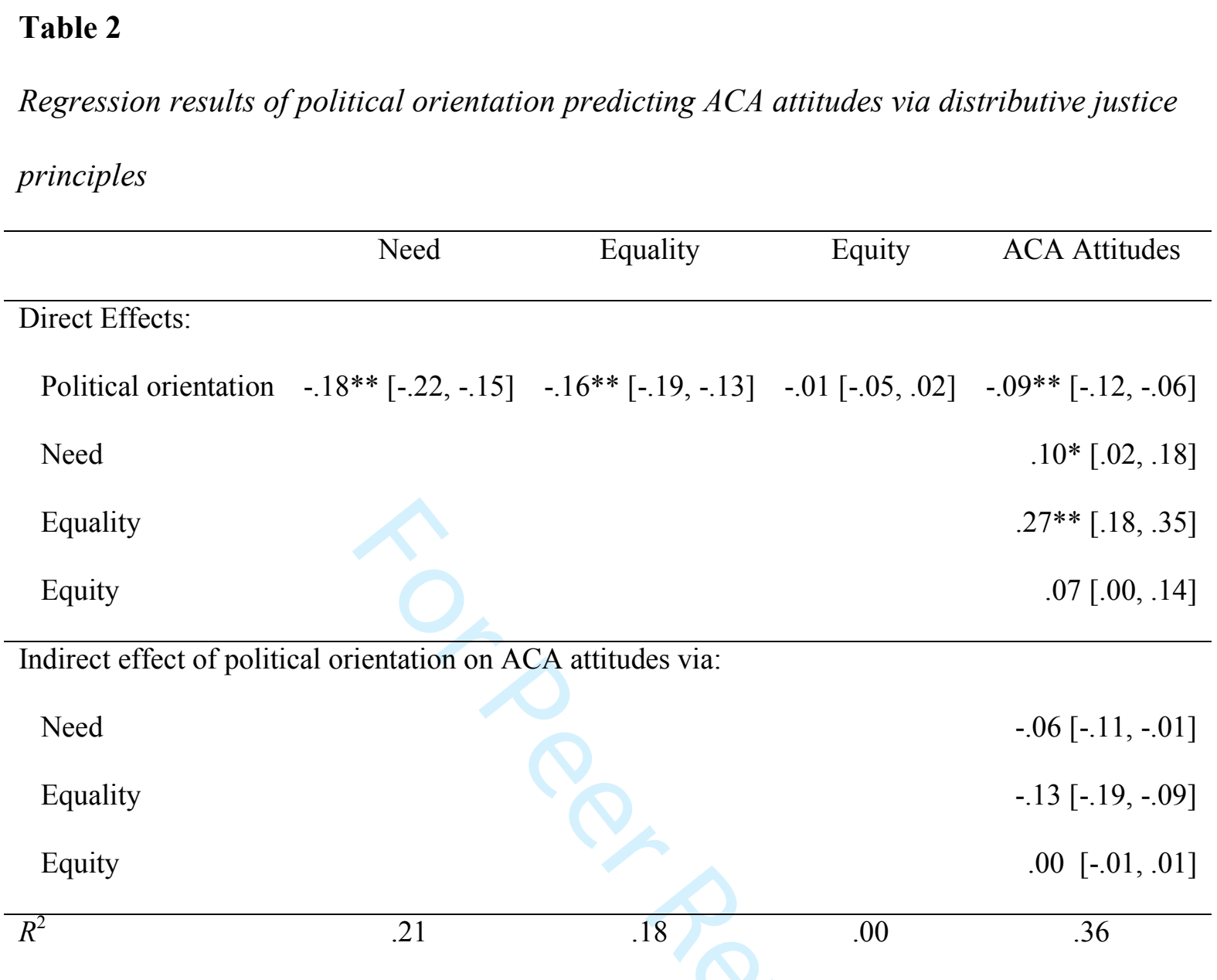

Note. ${ }^{* *} p<.001,{ }^{*} p<.05$

\section{Deservingness and anger as sequential mediators between political orientation and} 'Obamacare' attitudes

AMOS version 24.0 software was used to run a path analysis with deservingness and anger modeled as sequential mediators of the relation between political orientation and ACA attitudes. ${ }^{2}$ The model was fully saturated (i.e. $d f=0$ ), therefore no fit indices are reported. Standardized coefficients are shown. As shown in Figure 1, identifying as politically conservative (vs. liberal) significantly predicted lower deservingness, greater anger, and opposition to 'Obamacare'. Further, greater deservingness predicted less anger and greater support of 'Obamacare'. Finally, 
anger predicted less support of the ACA. Indirect effects of deservingness and anger were calculated using 5000 bootstrapped samples. The indirect effects of deservingness on anger, $95 \%$ CI $[.24, .36], p<.001$, and ACA attitudes, 95\% CI $[.01, .15], p=.028$, were significant. The indirect effect of deservingness via anger on ACA attitudes was also significant, 95\% CI [-.43, $.31], p<.001$. Therefore, as hypothesized, the relation between political conservatism and opposition to 'Obamacare' is partly explained by perceiving people as less deserving of the coverage benefits of the ACA and greater anger about the ACA itself.

\section{Figure 1}

Path analysis results of sequential mediation

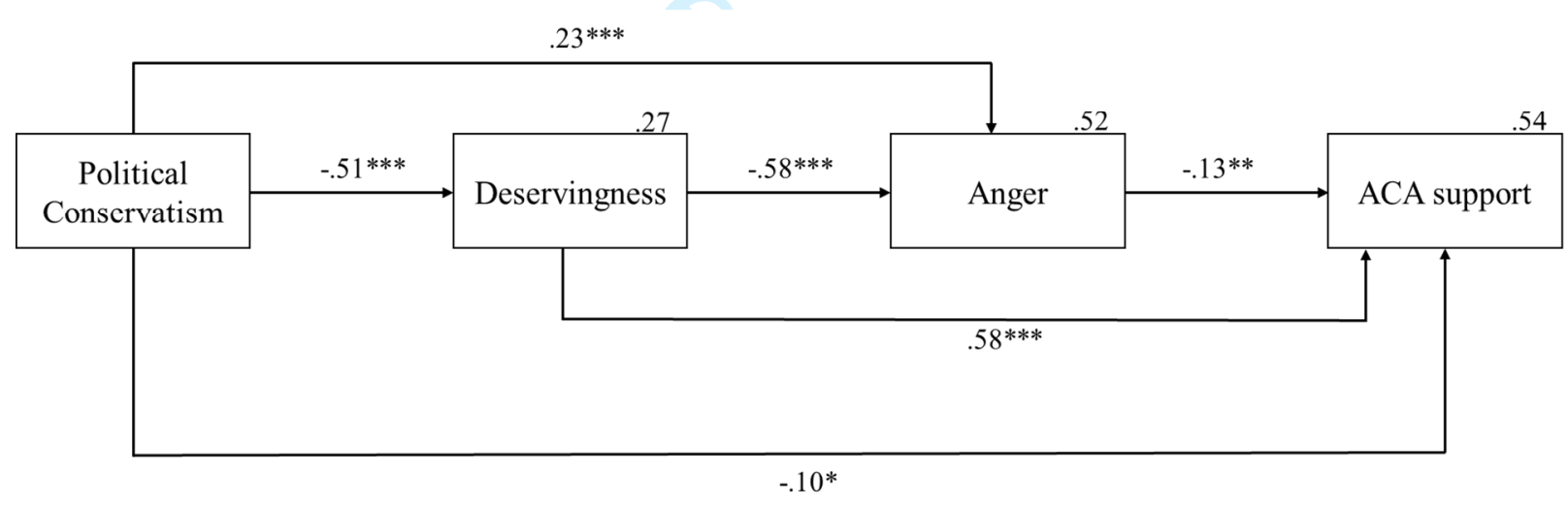

Note. $* * * p<.001, * * p<.01, * p<.05$.

\section{Exploratory Analysis}

Using PROCESS model 8, we also conducted an exploratory post hoc moderated mediation analysis. Specifically, we investigated political orientation as a moderator of the proposed deservingness $\rightarrow$ anger $\rightarrow$ ACA attitudes mediation model. As shown in Table 3, lower deservingness and higher political conservatism significantly predicted greater anger about the ACA. The interaction between deservingness and political orientation predicting anger was 
not significant. For the regressions predicting ACA attitudes, greater deservingness, selfidentification as politically liberal (vs. conservative) and less anger significantly predicted ACA support. The interaction between deservingness and political orientation predicting ACA attitudes was only marginally significant, $p=.06$. Simple slope analyses revealed that the positive relation between deservingness and ACA support was stronger for liberals $(b=.44, p<.001)$ versus conservatives $(b=.36, p<.001)$. The Johnson-Newman method did not reveal any transition points. There was also a significant indirect effect of deservingness on ACA attitudes via anger. This indirect effect was the same for liberals $(b=.05,95 \%$ CI $[.01, .10])$ and for conservatives $(b=.05,95 \% \mathrm{CI}[.01, .09])$. Therefore, anger mediated the relation between deservingness and ACA support, and the association between deservingness and ACA support was stronger among political liberals than conservatives.

\section{Table 3}

Regression results of the moderated mediation analysis

\begin{tabular}{lcc}
\hline \multicolumn{1}{c}{ Criterion variable: } & Anger & ACA Attitudes \\
\hline Predictor variable: & $-.66^{* *}[-.75,-.57]$ & $.40^{* *}[.34, .46]$ \\
Deservingness & $.13^{* *}[.08, .17]$ & $-.03^{*}[-.06,-.01]$ \\
Political orientation & $.01[-.02, .04]$ & $-.01^{+}[-.03, .00]$ \\
DESxPO & -- & $-.07^{*}[-.12,-.02]$ \\
Anger & .52 & .55 \\
\hline$R^{2}$ & &
\end{tabular}

Note. ${ }^{* *} p<.001,{ }^{*} p<.05,{ }^{+} p=.06$. 


\section{Fact-based ACA knowledge and political orientation as predictors of ACA support}

To explore whether knowledge and political orientation uniquely predict support for the ACA, a regression analysis was conducted. Knowledge, political orientation, and their interaction were entered as predictors of ACA attitudes. The model accounted for much of the variance in ACA attitudes $\left(R^{2}=.35\right)$. As noted above, greater political conservatism significantly predicted opposition to the ACA, $b=-.35, p<.001, s r^{2}=.11,95 \%$ CI $[-.43,-.27]$. Greater factbased knowledge about the ACA significantly predicted greater support for the ACA, $b=+.39, p$ $<.001, s r^{2}=.14,95 \%$ CI $[+.31,+.47]$. The interaction was not significant, $b=+.01, p=.708, s r^{2}$ $=.00,95 \% \mathrm{CI}[-.06,+.09]$. Therefore, fact-based knowledge about the ACA and political orientation uniquely predict ACA attitudes.

\section{Discussion}

Healthcare reform continues to be a contentious issue in the US. It is clear reforming and implementing major overhauls to healthcare legislation in the U.S. requires a deeper understanding of the mechanisms by which political orientation shapes attitudes about health policy. The present study provides novel evidence on the relation between political orientation and attitudes toward the ACA. First, our findings highlight the importance of the philosophy underlying the policy. For healthcare reform to succeed a compromise between the justice principles preferred by conservatives and liberals may be necessary. Our findings showed that preferences to allocate healthcare resources based on need or equality accounted for, in part, the link between a liberal orientation and ACA support. This finding is consistent with research showing that, in general, liberals prefer to distribute resources based on need or equality (Bierbrauer \& Klinger 2002; Frey \& Powell, 2005; Mitchell et al., 2003). Unexpectedly, a preference for allocating healthcare based on equity was unrelated to political orientation and 
ACA attitudes. It is possible that equity was less relevant as the ACA is not premised on equitable allocations. Given that conservatives prefer equitable allocation of aid and resources (Mitchell et al., 2003; Skitka \& Tetlock, 1992, 1993), it is possible that healthcare programs consistent with this justice principle might be preferred by conservatives.

As expected, political conservatives (vs. liberals) reported lower deservingness and in turn experienced greater anger and opposition to the ACA. This deservingness $\rightarrow$ anger $\rightarrow$ aid allocation pattern is consistent with theory and research on deservingness in several aid domains (Brandt, 2013; Rudolph et al., 2004; Skitka \& Tetlock, 1993; Weiner, 2006; Weiner et al., 2011; Zucker \& Weiner, 1993). In general, those perceived to be responsible or having control over their circumstances tend to be rated as less deserving (Feather, 1999; Weiner, 2006). This pattern of results highlights the significance of deservingness in guiding healthcare attitudes and policies. Other research shows that when conservatives perceive claimants as deserving, or not responsible for their plight, they are willing to provide aid. Conservatives may rely on different information in making deservingness judgments (see also Brandt, 2013). The weak correlation between deservingness and equity in the present research $(r=.20)$ suggests that conservatives' assessment likely has to do with issues beyond equity, or perhaps distributive justice. In exploring this topic further, researchers might consider the role of other types of justice, such as procedural justice, or the notion that fairness evaluations are connected to how decisions are made and how people are treated (e.g. for reviews see Tyler et al., 1997; Tyler, 2012; Vermunt \& Steensma, 2016). According to the group value model (Lind \& Tyler, 1988; Tyler, 1989), trust (i.e. good intentions, treating everyone fairly), standing (i.e. respect) and neutrality (i.e. unbiased) underlie procedural justice judgements with respect to the fairness of third parties such 
as an authority, like the government. Political conservatives might have opposed the ACA because they did not perceive the Obama government to extend trust, respect, or to be unbiased. Related work on morality reveals that political liberals and conservatives differ in their moral foundations. Of particular relevance to the present research, liberals tend to rely more heavily on the moral foundations of harm/care or fairness/reciprocity when making moral decisions compared to political conservatives (Graham, Nosek \& Haidt, 2009, Studies 1 and 2). While it might appear that this could suggest that political liberals care more about fairness than conservatives, the items used to tap fairness/reciprocity equate fairness primarily with equality (vs. equity). Indeed, when the items did not rely on principles of equality narrowly, there were no differences between liberals and conservatives (Graham et al., 2009, Study 3). This is not to say that constructs such as moral foundations or moral mandates (Skitka, 2002) are irrelevant. Indeed, research suggests that these factors can impact fairness evaluations greatly (Mullen \& Skitka, 2006; Skitka, Bauman, \& Mullen, 2016).

The present results concerning sympathy demonstrated that a politically liberal (vs. conservative) orientation related to experiencing greater sympathy, similar to previous research (Skitka \& Tetlock, 1992, 1993; Skitka 1999; Skitka et al., 2002). Sympathy was also associated with higher deservingness ratings, and favorable ACA attitudes. These correlations suggest that sympathy for recipients of healthcare aid may also play a key role in support (vs. opposition) to policies akin to the ACA.

A politically conservative orientation related to less fact-based knowledge about the ACA. One potential explanation for conservatives' lower knowledge about the details of the ACA could be a lack of motivation or interest to learn about it. Individuals tend to prefer information that is consistent with their existing beliefs, and it is possible that those leaning to 
the political right expected to disagree with the details of a Democrat-proposed and backed policy. Future research might explore whether factors like political bias or ideological scripts affect whether conservatives (and liberals) avoid learning about policies labelled as such. The fact that knowledge about the ACA uniquely predicted support for the policy and did not interact with ideology, illustrates the importance of relaying accurate information about policies.

Several limitations should be noted. First, our findings are based on a convenience sample of 436 American adults. Although our sample was diverse in several demographic characteristics, reflecting a similar diversity of the U.S. population, minority groups, and Independents and Republicans were under-represented. Second, given that our data are survey data and cross-sectional, conclusions about causality cannot be inferred. Although the assumed direction of our models are based on well supported theoretical perspectives (e.g. Feather, 1999; Weiner, 2006), it is nevertheless possible that the direction of some of our paths could be reversed or reciprocal.

While the majority of Americans tend to favor some form of federal healthcare support, a large chasm between conservatives and liberals exists regarding the extent and the means to achieve this. At the heart of the matter lies diverging political and philosophical views about fundamental issues such as deservingness, fairness and justice. At the same time, factual knowledge is of equal importance. Finding the means to bridge the gap regarding healthcare reform will remain a significant challenge for U.S. policymakers. Our work highlights a few of the major issues that they might wish to consider. 
Obamacare 21

\section{Footnotes}

${ }^{1}$ Attributions of responsibility were also assessed but given the extensive statistical overlap with deservingness were not included in analyses, as doing so created redundancy in the model. Models estimated with responsibility in place of deservingness revealed the same pattern of findings.

${ }^{2}$ A model with sympathy was also run; however, the direction of the coefficient for sympathy predicting attitudes changed direction. Another model was run removing anger, and the sign for sympathy again changed direction. Therefore, sympathy was dropped from the final model presented here. Full details are available from the first author. 


\section{References}

Adams, J. S. (1965). Inequity in social exchange. Advances in Experimental Social Psychology, 2(0), 267-299.

Applebaum, L. D. (2001). The influence of perceived deservingness on policy decisions regarding aid to the poor. Political Psychology, 22, 419-442.

Baumert, A., \& Schmitt, M. (2012). Some hypotheses on cross-cultural differences in the impact of resource type on the preferred principle of distributive justice. In K. To“rnblom \& A. Kazemi (Eds.), Handbook of social resource theory. New York: Springer.

Bierbrauer, G., \& Klinger, E. W. (2002). Political ideology, perceived threat, and justice towards immigrants. Social Justice Research, 15, 41-52.

Bodenheimer (2005). The political divide in health care: A liberal perspective. Health Affairs, 24(6), 1426-1435.

Brandt, M.J. (2013). Onset and offset deservingness: The case of home foreclosures. Political Psychology, 34(2), 221-238.

Christiansen, N. D., \& Lavine, H. (1997). Need-efficiency trade-offs in the allocation of resources: Ideological and attributional differences in public aid decision making. Social Justice Research, 10, 289-310.

Cohen, R. L., \& Greenberg, J. (1982). The justice concept in social psychology. In J. Greenberg and R. L. Cohen (Eds.), Equity and justice in social behavior. New York: Academic Press.

Deutsch, M. (1975). Equity, equality, and need: What determines which value will be used as the basis of distributive justice? Journal of Social Issues, 31(3), 137-149. 
DiJulia, B., Firth, J., \& Brodie, M. (August 20, 2015). Kaiser Health Tracking Poll: August 2015. Retrieved from Kaiser Family Foundation: http://www.kff.org/health-costs/pollfinding/kaiser-health-tracking-poll-august-2015/

Feather, N. T. (1985). Attitudes, values, and attributions: Explanations of unemployment. Journal of Personality and Social Psychology, 48, 876-889.

Feather. N. T. (1999). Judgments of deservingness: Studies in the psychology of justice and achievement. Personality and Social Psychology Review, 3(2), 86-107.

Fischer, R., \& Smith, P. B. (2003). Reward allocation and culture: A meta-analysis. Journal of Cross Cultural Psychology, 34, 251-286.

Fiske, A. P. (1992). The four elementary forms of sociality: Framework for a unified theory of social relations. Psychological Review, 99, 689-723.

Foa, E. B., \& Foa, U. G. (1976). Resource theory of social exchange. In J. W. Thibault, J. T. Spence, and R. C. Carson (Eds.), Contemporary topics in social psychology. Morristown, NY: General Learning Press.

Frey, R. A., \& Powell, L. A. (2005). Beyond left-right ideology in the study of justice perception: Interdependent and independent distributive worldviews in Jamaica and New Zealand. Journal of Cross-Cultural Psychology, 36, 117-146.

Gilens, M. (1995). Racial attitudes and opposition to welfare. Journal of Politics, 57, 994-1014.

Gilens, M. (1999). Why Americans hate welfare: Race, media, and the politics of antipoverty policy. Chicago: The University of Chicago Press.

Graham, J., Nosek, B. A., \& Haidt, J. (2009). Liberals and conservatives rely on different sets of moral foundations. Journal of Personality and Social Psychology, 95, 1029-1046. 
Gross W, Stark TH, Krosnick J, et al. (2012). American's attitudes towards the affordable care act: Would better public understanding increase or decrease favorability? Unpublished manuscript. Retrieved from: http://www.gsood.com/research/papers/ACAKnowledgeFavorability.pdf Hayes, A. F. (2018). Introduction to mediation, moderation, and conditional process analysis: A regression-based approach. New York: The Guildford Press.

Henry, P., Reyna, C., \& Weiner, B. (2004). Hate welfare but help the poor: How the attributional content of stereotypes explains the paradox of reactions to the destitute in America. Journal of Applied Social Psychology, 34, 34-58.

Huddy, L., \& Feldman, S. (2006). Worlds apart: Blacks and Whites react to Hurricane Katrina. Du Bois Review, 3, 97- 113.

Jasso, G., Tornblom, K. Y., \& Sabbagh, C. (2016). Distributive justice. In C. Sabbagh \& M. Schmitt (Eds.), Handbook of social justice theory and research (pp. 201-218). New York, NY: Springer.

Jost, J. T. (2006). The end of the end of ideology. American Psychology, 61 (7), 651-670.

Jost, J. T., \& Kay, A. C. (2010). Social justice: History, theory, and research. In S. T. Fiske, D. T. Gilbert, \& G. Lindzey (Eds.), Handbook of social psychology ( $5^{\text {th }}$ edition) (pp. 11221165). New Jersey, US: John Wiley \& Sons, Inc.

Kirsch, R. (2013). The politics of Obamacare: Healthcare, money, and ideology. Fordham Law Review, 81, 1737-1747.

Kirzinger, A., Sugarman, E., \& Brodie, M. (2016). Data note: Americans'opinions of the Affordable Care Act. Retrieved from Kaiser Family Foundation website: 
http://kff.org/health-reform/poll-finding/data-note-americans-opinions-of-the-affordablecare-act/

Kirzinger, A., Wu, B., \& Brodie, M. (January 6, 2017). Kaiser health tracking poll: Health care priorities for 2017. Retrieved from Kaiser family foundation website: http://kff.org/health-costs/poll-finding/kaiser-health-tracking-poll-health-care-prioritiesfor-2017/

Kline, R. (2005). Principles and practice of structural equation modeling. New York: The Guilford Press.

Lane, R. E. (2001). Self-reliance and empathy: The enemies of poverty—and of the poor. Political Psychology, 22, 473-492.

Lind \&, E. A., Tyler, T. R. (1988). The social psychology of procedural justice. New York, NY: Plenum Press.

Matania, E., \& Yaniv, I. (2007). Resource priority, fairness, and equality-efficiency compromises. Social Justice Research, 20, 497-510.

Mitchell, G., Tetlock, P. E., Newman, D. G., \& Lerner, J. (2003). Experiments behind the veil: Structural influences on judgments of social justice. Political Psychology, 24 (3), 519547.

Morgan, G. S., Mullen, E., \& Skitka, L. J. (2010). When values and attributions collide: Liberals' and conservatives' values motivate attributions for alleged misdeeds. Personality and Social Psychology Bulletin, 36, 1241-1254.

Mullen, E., \& Skitka, L. (2006). Exploring the psychological underpinnings of the moral mandate effect: Motivated reasoning, identification, or affect? Journal of Personality and Social Psychology, 90, 629-643. 
Nelson, T. E. (1999). Group affect and attribution in social policy opinion. Journal of Politics, $61,331-362$.

Otto, K., Baumert, A., \& Bobocel, D. R. (2011). Cross-cultural preferences for distributive justice principles: Resource type and uncertainty management. Social Justice Research, $24,255-277$.

Paolacci, G., \& Chandler, J. (2014). Inside the Turk: Understanding mechanical turk as a participant pool. Current Directions in Psychological Science, 23(3), 184-188.

Pellegrini, R. J., Queirolo, S. S., Monarrez, V. E., Valenzuela, D. M. (1997). Political identification and perceptions of homelessness: Attributed causality and attitudes on public policy. Psychological Reports, 80, 1139-1148.

Pew Research Centre (April 7, 2015). A deep dive into party affiliation. Retrieved from: http://www.people-press.org/2015/04/07/a-deep-dive-into-party-affiliation/

Rawls, J. A. (1971). A theory of justice. Cambridge: Harvard University Press.

Reyna, C., Henry, P. J., Korfmacher, W., \& Tucker, A. (2006). Examining the principles in principled conservatism: The role of responsibility stereotypes as cues for deservingness in racial policy decisions. Journal of Personality and Social Psychology, 90, 109-128.

Rice, T., Unruh, L.Y., van Ginneken, E., Rosenau, P., \& Barnes, A.J. (2018). Universal coverage reforms in the USA: From Obamacare through Trump. Health Policy. Health Policy, https://doi.org/10.1016/j.healthpol.2018.05.007.

Rudolph, U., Roesch, S. C., Greitemeyer, T., \& Weiner, B. (2004). A meta-analytic review of help giving and aggression from an attributional perspective: Contributions to a general theory of motivation. Cognition and Emotion, 18, 815-848. 
Sabbagh, C., \& Schmitt, M. (2016). Handbook of social justice theory and research. New York, NY: Springer.

Scott, J. T., \& Bornstein, B. H. (2009). What's fair in foul weather and fair? Distributive justice across different allocation contexts and goods. Journal of Politics, 71, 831-846.

Shirazi, R., \& Biel, A. (2005). Internal-external causal attributions and perceived government responsibility for need provision: A 14-culture study. Journal of Cross-Cultural Psychology, 36, 96-116.

Skitka, L. J. (1999). Ideological and attributional boundaries on public compassion: Reactions to individuals and communities affected by a natural disaster. Personality and Social Psychology Bulletin, 25, 793-8.

Skitka, L. J. (2002). Do the means always justify the ends, or do the ends sometimes justify the means? A value protection model of justice reasoning. Personality and Social Psychology Bulletin, 28, 588-597.

Stitka, L., Bauman, C. W., \& Mullen, E. (2016). Morality and justice. In C. Sabbagh \& M. Schmitt (Eds.), Handbook of social justice theory and research (pp. 407-423). New York, NY: Springer.

Skitka, L. J., Mullen, E., Griffin, T., Hutchinson, S., \& Chamberlin, B. (2002). Dispositions, scripts, or motivated correction? Understanding ideological differences in explanations for social problems. Journal of Personality and Social Psychology, 83, 470-487.

Skitka, L. J., \& Tetlock, P. E. (1992). Allocating scarce resources: A contingency model of distributive justice. Journal of Experimental Social Psychology, 28, 491-522. 
Skitka, L. J., \& Tetlock, P. E.(1993). Providing public assistance: Cognitive and motivational processes underlying liberal and conservative policy preferences. Journal of Personality and Social Psychology, 65, 1205-1223.

Törnblom, K. Y. (1992). The social psychology of distributive justice. In K. Scherer (Ed.), Justice: Interdisciplinary perspectives (pp. 175-236). Cambridge: Cambridge University Press.

Tyler, T. R. (1989). The psychology of procedural justice: A test of the group-value model. Journal of Personality and Social Psychology, 57(5), 830-838.

Tyler, T. R., Boeckmann,, R. J., Smith, H. J., \& Huo, (1997). Social justice in a diverse society. Boulder, CO: Westview Press.

Tyler, T. R. (2012). Justice theories. In P. Van Lange, A. Kruglanski, \& T. Higgins (Eds.), Handbook of theories of social psychology. Thousand Oakes, CA: Sage.

Walster, E., Berscheid, E., \& Walster, G. W. (1973). New directions in equity research. Journal of Personality a,nd Social Psychology, 25, 151-176.

Weiner, B. (1980). A cognitive (attribution)-emotion-action model of motivated behavior: An analysis of judgment of help-giving. Journal of Personality and Social Psychology, 39, $186-200$.

Weiner, B. (2006). Social motivation, justice, and the moral emotions. Mahwah, NJ: Lawrence Erlbaum.

Weiner, W., Osborne, D., \& Rudolph, U. (2011). An attributional analysis of reactions to poverty: The political ideology of the giver and the perceiver morality of the receiver. Personality and Social Psychology Review, 15, 199-213. 
Vermunt, R., \& Steensma, H. (2016). Procedural Justice. In C. Sabbagh \& M. Schmitt (Eds.), Handbook of social justice theory and research (pp. 219-236). New York, NY: Springer.

Zucker, G. S., \& Weiner, B. (1993). Conservatism and perceptions of poverty: An attributional analysis. Journal of Applied Social Psychology, 23, 925-943. 